\title{
TENSÃO ENTRE LITERATURA E FILOSOFIA: A LINHA DE SUTURA PARA A COMPREENSÃO DE UMA MORAL CRISTÃ
}

\author{
Pâmela C. Damasceno dos Santos ${ }^{1}$
}

\section{RESUMO:}

O presente trabalho propõe-se a interrogar o texto literário de José Saramago, "O Evangelho segundo Jesus Cristo", à luz das premissas filosóficas articuladas por Friedrich Nietzsche, registradas na obra "Genealogia da Moral"”. Assim, põe-se em exame a validade exemplar da obra ficcional que, ao esboçar um novo modelo de cristianismo, acaba apropriando-se de determinados conceitos morais culturalmente construídos.

PALAVRAS-CHAVE: Cristianismo; Culpa; Literatura; Filosofia; Fissuras.

\begin{abstract}
:
The current work intends to question José Saramago's "O Evangelho Segundo Jesus Cristo", basing the study on the philosophical premises by Friedrich Nietzsche, on the work "On the Genealogy of Morality". From that, it is put under examination the exemplar validity of the fictional work that, trying to draw a new Christian model, takes certain moral concepts culturally built.
\end{abstract}

KEYWORDS: Christianity; guilt; Literature; Philosophy; fissures.

Recebido em: 10/05/2013 - Aprovado em: 10/07/2013 - Disponibilizado em: 15/08/2013

\footnotetext{
${ }^{1}$ Discente do Programa de Pós-Graduação em Letras, especialidade Literatura Comparada na Universidade Federal do Rio Grande do Sul (UFRGS); pamelacris@ terra.com.br

2 Título original: "Zur Genealogie der Moral”.
} 
Valendo-me dos Estudos Literários Comparados, com enfoque na relação interdisciplinar que a Literatura entretém com a Filosofia, o presente trabalho põe em relação o objeto de criação literária Saramaguiano, "O Evangelho segundo Jesus Cristo", à luz das premissas filosófico articuladas por Nietzsche, registradas na obra "Genealogia da Moral". Duas vozes dissonantes, heterogêneas, descompassadas que, quando aproximadas, atestam as nítidas diferenças que norteiam essas duas construções discursivas.

Inscritos em um contexto no qual os discursos são tidos como local de constante tesão, onde se inserem dialeticamente estruturas textuais e extratextuais, a análise operada propõe-se, igualmente, a esboçar as relações estabelecidas com os elementos extratextuais, no caso, os discursos morais e religiosos historicamente construídos. Desta forma, não se limita o alcance interpretativo dos estudos e se faz possível deslocar, para um campo amplo de análise, as produções confrontadas. Uma vez delimitados os contornos que orientam as análises tecidas, passemos ao entendimento dos fundamentos teóricos propriamente.

A filosofia, lógica em sua própria essência, encontra-se cingida por um sistema de regras que refletem um esforço de ordenação do pensamento a que estão submetidos certos discursos. Faz-se importante acrescentar, entretanto, que essas idéias filosóficas, condicionadas a determinados critérios de argumentação, ainda assim, não conseguem ser delimitadas se dissociadas da retórica que as atravessa e permanece a serviço de fins especiais de resolução de problemas.

Ao passo que se esboçam os contornos do pensamento filosófico, emerge a criação discursiva, puramente retórica, cuja linguagem encontra-se incorporada a um contexto estruturador de mundo, nesse caso, representativo da experiência do literário. $\mathrm{O}$ universo literário, condicionado ao domínio do sensível, tece suas tramas discursivas suscetíveis à imprevisibilidade das transformações poético-criativas. $\mathrm{Na}$ dimensão da linguagem poética, a atração intuitiva pelo pensamento ordenado, então característica dos sistemas filosóficos, dilui-se, uma vez que não se consegue determinar as forças éticas e morais que determinam as trajetórias tensas dos personagens.

Desta maneira, na delimitação das tramas particulares encenadas, o discurso literário articula um verdadeiro ‘jogo amoral', ético e linguístico, esboçando os 
contornos de conceitos, por vezes, dissonantes. Assim, a literatura mostra-se capaz de promover recortes no mundo ordenado, no qual operam esses sistemas filosóficos de pensamento, e introduz, de maneira oblíqua, a dissolução de seus limites. Nesse sentido, a linguagem literária, puramente retórica, revela uma postura cética para com a simples adesão a algumas regras e premissas lógicas.

$\mathrm{Na}$ medida em que a função poética da linguagem, que se caracteriza por sua capacidade criadora de mundo, ganha força estruturante, o discurso literário liberta-se das restrições e estreitezas éticas e culturais. Imersa nessa perspectiva, a experiência estética do literário é tomada como aspecto não conciliável com a ordem moral, desencadeando uma nítida suspensão entre a sensibilidade estética e o que foi culturalmente produzido - determinado discursivamente como produto de elos lógicos do pensamento.

O discurso literário que não se deixa determinar, baseado em distinções sensíveis, cria um lugar a parte dentro dos sistemas constituídos, concebendo outra realidade que não a orientada por princípios moralizantes. Assim, a experiência estética, segundo $\mathrm{Hegel}^{3}$, pode constituir-se enquanto figuração estética do espírito, um verdadeiro desdobramento do espírito daquilo que ele tem de livre e autônomo.

Nesse sentido, a sensibilidade cultivada pela experiência do literário, bem como o gosto pelo estético e pelo desvendamento de relações epidérmicas, mais emocionais, permite com que a literatura, valendo-se da análise de alguns pressupostos filosóficos, possa descobrir as zonas de inquietação e indeterminação que perpassam o pensamento ordenado. Processa-se, desta maneira, a abertura a zonas de cromatismos, para que a sensibilidade venha a trabalhar nos conceitos filosóficos discursivos, encontrando, por vezes, a linha de fissura dessa superfície textual.

Assim, ao transmitir pensamentos filosóficos em relatos ficcionais, a literatura pode promover fissuras na filosofia, desconstruindo ou dilatando as categorias então convencionadas e possibilitando a criação de diferentes modos de conceber a realidade. Inscritos nessa conjuntura, dá-se a suspensão dos juízos conceitualmente determinados à luz de uma profusão de sentimentos desviantes que, quase invariavelmente, o discurso literário costuma evocar.

\footnotetext{
${ }^{3}$ Intuição fenomenológica de Hegel.
} 
A dimensão do literário, dessa forma, trata de criar e desdobrar casos singulares nos quais se faz necessário lançar mão de vários conceitos filosóficos contraditórios entre si, promovendo a abertura a uma pluralidade de sentidos e significações, e corroborando para que haja uma confluência desses diferentes valores no universo ficcional revelado. Produz-se, assim, uma tensão consensual que tende para a inversão de todos os valores, o que se dá a margem das trajetórias tensas de ação construídas.

Os enredos literários possibilitam, pois, reaver as idéias filosóficas, marcadas pela preponderância da lógica, deformando essas concepções a partir de sentimentos muito particulares. Com isso, faz-se possível promover o desmascaramento de princípios moralizantes e éticos, legitimados como produtos de saberes formalmente ordenados.

No universo ficcional delimitado pelas tramas poéticas, microcosmos e macrocosmos literário encontram-se em profunda tensão, em uma tessitura na qual nenhuma ordem, seja ela social, moral ou ética permanecerá intacta face aos desdobramentos protagonizados. Ao passo que o enredo narrativo é construído, à sombra da linguagem literária, promovemse, constantemente, denúncias das inconsistências intrínsecas que permeiam essa ordem, atestando que a mesma possui fissuras em sua lógica.

A partir das proposições teóricas consideradas até o presente momento, fazse possível esboçar os contornos e peculiaridades encerrados pelos discursos filosófico e literário. A retórica, tomada em sua condição de superioridade face ao domínio do lógico, conduz a um estudo do discurso literário enquanto capaz de tangenciar os valores filosóficos, o que se dá à medida que os modula, os envolve e os põe em cheque.

Inscritos nesse contexto, a ênfase do presente ensaio se configura à sombra da constatação de um aspecto lacunar no que tange aos estudos teóricos então desenvolvidos. A partir do traçado de um paralelo entre as duas produções, frutos de nossas análises, perceber-se-á, no entanto, que a linguagem literária assume uma configuração bastante particular e destoante das constatações até o momento esboçadas.

Interrogando o texto literário de José Saramago em sua relação com a esfera de conhecimento filosófico, ponho em exame a validade exemplar da obra ficcional que, ao esboçar um novo modelo de cristianismo, acaba apropriando-se de determinados conceitos morais 
culturalmente construídos ('culpa', 'castigo'), tornando-os motivo de uma exposição inovadora. Nesse sentido, ademais de analisar a validade exemplar do literário, proponho, a partir do traçado dessa relação magistral, uma reflexão acerca de certos modos éticos e morais de entender o mundo.

A sociedade cristã, concebida enquanto sociedade da culpa e do castigo, é criada e recriada pelos autores cotejados, conformando-se como microcosmos onde se protagonizam as mais variadas ânsias e extravasamentos do ser. Delimita-se, dessa maneira, um espaço humano no qual se legitimam ou se desconstroem valores morais e éticos, projetando, à luz da experiência imaginativa do literário e do pensamento filosófico, diferentes maneiras de conceber o tradicional mundo judaicocristão.

Nesse contexto, José de Sousa Saramago (Azinhaga, 1922 - Lanzarote, 2010), romancista responsável pelo efetivo reconhecimento internacional da prosa em língua portuguesa, valendo-se de uma postura assumidamente ateísta, publica em 1991 a obra "O evangelho segundo Jesus Cristo", recompondo com um novo traçado o tradicional universo judaicocristão. A obra, assim como outros romances anteriores, problematiza a leitura dada a aspectos da realidade material, nesse caso, a gênese da sociedade cristã é colocada sob o olhar atento do escritor português.

Desta forma, à sombra das constatações que consagram a aparência estética, determinante da função poética, um reflexo da capacidade criadora de mundo delimitada pela linguagem, erige-se a produção de Saramago que, utilizando a linguagem criativa como substância da criação, procede com a reinvenção da gênese da sociedade cristã. Inscrita nessa perspectiva, a experiência do literário tece seus desdobramentos à medida que o escritor português interpreta e reinterpreta, de uma maneira bastante singular, $\mathrm{O}$ Evangelho segundo Jesus Cristo $-e$ porque não dizer "O evangelho segundo Saramago".

O romance está inscrito no cerne de um mundo cristão, e, embora fora do cristianismo, não se propõe de nenhum modo o tentar negar, antes revela um latente desejo de apropriar-se dele. No saldo final, não nos resta dúvidas em constatar que a obra não é um evangelho, mas sim um romance que parte de acontecimentos históricos fundamentais para congregar os valores de uma das principais religiões do mundo $-\mathrm{o}$ Cristianismo. 
Jesus, Maria e José vivem na Galiléia de dois mil anos atrás, como reza a Bíblia, porém Saramago impõe à história uma visão mundana dos fatos relativos ao nazareno. Assim, o personagem principal, um homem sofredor, imerso na sua humanidade, foi concebido como todos os homens, cometeu os mesmos pecados, teve as mesmas sensações, partilhou das mesmas dúvidas e sentiu-se fragilizado diante da morte. Revestiram-se os personagens bíblicos de um traçado humano, não divino, inscrevendo-os no panorama sócio-cultural judaico de vinte séculos atrás.

Nessa conjuntura, a recriação da figura de S. José na fábula de Saramago surge como um personagem marcado pelo sentimento de culpa, o que se deve ao fato de não ter alertado os pais dos inocentes sobre o fim que aguardava as crianças ${ }^{4}$. Tal recriação cristaliza-se em uma criatura atormentada, cujo final será trágico, culminando por transmitir ao filho esse mesmo sentimento culposo: "Disse o anjo: sobre a cabeça dos filhos há-de sempre cair a culpa dos pais, a sombra da culpa de José já escurece a fronte do teu filho". (SARAMAGO, 2005, p. 93)

\footnotetext{
${ }^{4}$ Episódio do infanticídio decretado por Herodes.
}

Assim, José aparece como uma das figuras principais do romance - um lugar que o carpinteiro não possuía na Bíblia. Em ocasião da situação aludida, ele é atormentado por crises ferozes de arrependimento e culpa. José, mesmo ciente dos fatos, preferiu salvar a vida do filho ao alertar a população face ao episódio do infanticídio decretado por Herodes. Esse complexo de culpa vai acompanhá-lo até a morte, na cruz, acusado de terrorismo.

Da mesma maneira, ao passo que a trama do romance é desdobrada, dá-se o incessante desvelamento do protagonista, filho de José, em seu estar no mundo. Jesus se dirá de inúmeras maneiras e terá de "perguntar" e "perguntar-se" para compreender sua vida 'elo por elo' e, dessa maneira, desmistificar a insondável complexidade que perpassa a questão da culpa herdada: "Remorso por aquilo que não fez, mas de que há-de-ser, enquanto viva, ó insanável contradição, o primeiro culpado." (SARAMAGO, 2005, p.184).

Nesse sentido, os ecos da tradição fazem-se visíveis sobre o substrato de criação literária saramaguiano, instaurando as bases estruturantes a partir das quais se firma um universo singular que, embora regido por significações e preceitos diferenciados, ainda preservam fragmentos 
indissolúveis da tradição legada pelos ancestrais ao longo de mais de dois mil anos. Essa nova dimensão do universo cristão encerrada pelo literário, suscitando implicações de diversas ordens, erige-se enquanto promessa de ordenação dos descompassos identificados pelo escritor português no que concerne aos acontecimentos representativos do Cristianismo.

Assim, o romancista José Saramago, responsável por aliar conhecimento moral a uma sensibilidade estética, inscreve sua história dentro de uma determinada ordenação de mundo e, em face de um sistema de valores estabelecidos e legitimados por uma conjuntura cultural cristã, busca recursos narrativos para, dessa maneira, preservar a estreiteza desses valores. Sua obra incorpora regras e ditames morais como o 'pecado', a 'culpa' e o 'castigo' que, operando em seu universo discursivo, funcionam como valores estruturantes da trama, delimitando o traçado dos personagens.

Diante de uma sociedade da 'culpa' e do 'castigo', atravessada por uma ideologia cristã que reside na afirmação desses valores, o mundo literário de Saramago pode ser concebido enquanto universo fechado (impenetrável), regido por regras e costumes morais que, mesmo em face da latente disposição das massas emocionas dos personagens, não se faz suficiente para romper com a estreiteza dessas convenções historicamente construídas. Nele, os valores então elucidados, com ênfase na questão da culpa, mantêm o mesmo espaço já ocupado no contexto sócio-cultural, como reflexos de consensos morais estabelecidos.

Uma análise da produção literária desse escritor permite observar, portanto, que a fábula em questão não corrompe nem diviniza o mundo judaico-cristão, trazendo o que chamamos representações do "bem" e do "mal". Humaniza, em seu sentido mais profundo, porque faz viver a todos os seus personagens bíblicos, encerrando em seu poder humanizador uma multiplicidade de contradições desdobradas pelo enredo narrativo.

Tomando por referência esse contexto, uma vez atestada a primazia da retórica (do literário) face ao tradicional domínio da lógica ${ }^{5}$, suscita-se a possibilidade de tratar as obras da filosofia como obras da literatura. Assim, passou-se

\footnotetext{
5 Segundo proposições tecidas em HABERMAS, Jürgen. "Excurso sobre o Nivelamento da Diferença Genérica entre Filosofia e Literatura", in O Discurso Filosófico da Modernidade. Lisboa, Dom Quixote. 1990.
} 
a observar que o discurso filosófico, não raras as vezes, encontrava-se atravessado pela presença de elementos ficcionais, metafóricos e, em geral, imerso em aditivos literários.

À luz dessa premissa aludida, é possível atentar, então, para o caráter literário dos escritos de Friedrich Wilhelm Nietzsche (1844-1900), discursos cingidos por uma força literariamente elucidativa e retoricamente esclarecedora. Nietzsche, munido de certo ideário filosófico, propõese a firmar o olhar sobre dadas construções e modos de conceber a história universal ordenações de mundo historicamente determinadas como produtos de uma genealogia; e, no traçado de suas constatações, deixa transparecer o encontro que se processa entre suas reflexões filosóficas e os conflitos representados pela Literatura.

Assim, o filósofo alemão, uma vez incumbido da tarefa de refletir acerca das incongruências de certos modos estruturantes de conceber os axiomas morais que regem a sociedade cristã, valese do pensamento filosófico e de sua força retórica enquanto métodos críticos para, dessa maneira, desmembrar as nuances da gênese dessa construção social cristã, calcada, quase invariavelmente, em uma teologia escatológica ${ }^{6}$.

Nesse contexto, o Cristianismo emerge aos olhos do filósofo enquanto religião de caráter normativo que, articulando jugos sociopolíticos, propõe-se a controlar as disposições emocionais de seus fiéis. Tal doutrina, apropriando-se de valores morais rigidamente ascéticos, converte-os em 'autênticos' instrumentos da cultura, impondo resignações e renúncias às vivências humanas.

Assim, em sua obra Genealogia da Moral (1998), o filósofo aponta as origens dessa moral alicerçada em valores puramente cristãos. Nessa obra, a gênese da moral social é posta à prova, bem como seus propósitos ideológicos no que tange aos conceitos de 'verdade', 'universalidade', 'essência' e 'Deus'. Nietzsche, percebendo que os valores vividos na sociedade moderna estavam intimamente relacionados a essa moral tradicional cristã, tece suas críticas ao Cristianismo e a sua maneira de forjar tais valores.

\footnotetext{
6 Escatologia (do grego antigo $\varepsilon \sigma \chi \alpha \tau o \varsigma$, "último", mais o sufixo -logia) é uma parte da teologia e filosofia que trata dos últimos eventos na história do mundo ou do destino final do gênero humano, comumente denominado como fim do mundo.
} 
Nesse contexto, o Cristianismo passa a esboçar um traçado de notoriedade ao enobrecer as fraquezas humanas, em uma compreensão na qual o homem é concebido como ser envolto em pecados, débil, dependente, que não pode ser entendido se dissociado de seu teor de humanidade. A doutrina cristã, criadora e essencialmente criativa dessas relações moralizantes, reveste-as de contornos mais nítidos, legitimando-as enquanto representações marcadas por um forte teor de submissão.

O então alicerce ético do Ocidente é fundamentado nessas representações morais cristãs, que ainda vigoram em meio ao contexto sócio-histórico cultural contemporâneo, ditando regras de conduta morais e éticas, definindo noções de "bem" e "mal" e, desta forma, instaurando as bases para que esses pares antípodas adquiram valor simbólico e condicionem as ações humanas. $\mathrm{O}$ sujeito que se delimita a sombra desse processo, uma vez imerso nessa lógica, encontra-se cingido pela estreiteza desses ditames de interdição humana e, em sua relação com o mundo, constitui-se na e pela legitimação dessas representações.

Tendo em vista essas considerações, podemos depreender que a filosofia de Nietzsche procede a uma desmistificação dos conceitos de 'religião', 'moral' e 'filosofia universais'. Assim, a força simbólica congregada pelas idéias de 'pecado', 'culpa' e 'remissão dos pecados' emerge como reflexo dessa dogmática, na qual é feita uma construção do mundo natural como sendo mal. Com efeito, o "mundano" e a "sabedoria do mundo" adquirem um traçado singular, legitimando-se como verdadeiras alegorias do "pecado", do "desvio" e das "tentações", produtos da falibilidade constitutiva da essência humana.

Através dessas constatações, podemos depreender que, em suma, as críticas tecidas por Nietzsche recaem sobre o Cristianismo e não sobre a cristianidade. Inscrito nesse contexto, Nietzsche sugere a adoção de um "cristianismo autêntico", este concebido enquanto prática - uma vida semelhante a aquele que morreu na cruz. Na delimitação desses contornos, o cristianismo estaria longe de ser, portanto, um dogma, uma instituição, ou mesmo, uma doutrina.

O comportamento cristão, para Nietzsche, deve firmar-se na ação, estabelecendo-se no plano terreno. Imersa nessa realidade, entretanto, a religião cristã, essencialmente formadora de valores, prefere concebê-lo "no além", forjando uma doutrina que domestique o 
homem e o incuta o 'pecado', o 'castigo' e, principalmente, a 'culpa' como alicerces morais reveladores da condição humana.

Assim, a relação castigo e culpa é entendida pela filosofia nietzschiana como sendo algo gerado pelo próprio homem, não se instituindo enquanto sentença dada por Deus. Nessas circunstâncias, a culpa seria um produto do desejo humano, reforçando ainda que este desejo, não raras às vezes, pode transformar-se em castigo ou em juízo punitivo. Nietzsche conclui que o cristianismo reforça com contornos mais nítidos essa tendência inerente ao homem, em que o próprio indivíduo conforma-se como responsável por revestir-se com seu teor de humanidade e, portanto, por assumir-se falível.

Essas idéias, entretanto, não encontram eco na realidade para Nietzsche, uma vez que, em seu pretendido "cristianismo autêntico" a estreiteza dessas noções de 'pecado', 'culpa' e 'castigo' perdem sua força simbólica, diluindo-se mediante a prática da solidariedade humana. Suas reflexões filosóficas convergem no sentido de suscitar um questionamento sobre a pertinência dessas representações morais então instaurados e vigentes no universo cristão.

Tomando por referência as considerações tecidas até o presente momento, no que tange às produções, frutos de nossas análises, pode-se constatar que o filósofo, diferentemente do romancista, mostra-se capaz de refletir acerca dos problemas de certos modos morais e religiosos de conceber o mundo, o que se dá a partir da delimitação de pensamentos verdadeiramente desviantes. Nesse caso, o discurso filosófico encarrega-se de esboçar a linha de fissura do saber culturalmente produzido, ao passo que o discurso literário se legitima à sombra da afirmação desses valores éticoreligiosos, produtos do dogmatismo.

Inscrito nessa lógica, o substrato de criação literária saramaguiana incorpora regras morais, operando em seu universo discursivo através da estreiteza desses preceitos. Desta forma, não corrompe a moral: 'pecado', 'culpa' e 'castigo' funcionam como valores estruturantes da obra, delimitando o traçado dos personagens. $\mathrm{O}$ autor português inscreve sua história dentro de uma determinada ordenação de mundo e, no traçado de sua trama ficcional, encontra maneiras de preservar a rigorosidade dessas construções.

Assim, ainda que a representação estética do literário proponha-se, em certa medida, a investigar as convicções éticas, morais e religiosas instauradas e, então, 
vigentes, a literatura, nesse caso, mostra-se incapaz de promover conjunturas desviantes no que concerne aos discursos morais e éticos, frutos de um saber formalmente construído. Muito antes, a criação saramaguiana legitima esses valores como matéria organizadora de mundo, motivos para a construção dos argumentos esboçados pela trama literária.

A incapacidade do romancista português, no tocante à superação desses conceitos morais, revela a imposição de uma ideologia cristã, que ganha notável importância na tessitura da obra. O discurso literário, ainda que produzido a partir de distinções sensíveis, deixa-se determinar, criando um lugar dentro dos sistemas construídos, concebendo uma realidade ficcional então orientada por princípios moralizantes.

Dessa maneira, pode-se inferir que a ideologia cristã na obra literária de Saramago reside na afirmação de valores como a 'culpa', o 'pecado' e o 'castigo, elementos que mantêm o mesmo espaço já ocupado no contexto cultural contemporâneo. Esse "formato" de cristianismo vai de encontro ao "cristianismo autêntico" preconizado por Nietzsche, um cristianismo do "nãoevangelho", em que a culpa, o pecado e o castigo perdem sua força simbólica, atestando as incongruências da ordem ideológica cristã.

Assim, ainda que Saramago se predisponha a oferecer uma "autêntica" visão dos acontecimentos, não conseguiu atingir a dimensão de um cristianismo autêntico (nietzschiano). A obra, em sua essência, tão somente transpõe para o contexto discursivo do romance, elementos extraídos da tradição cristã e transcritos, em toda sua dimensão simbólica, para o universo inventivo do escritor português. Embora "imoral" aos olhos de muitos leitores católicos, a obra não conseguiu desmistificar valores morais, superá-los e, desta forma, atingir ao cristianismo genuíno preconizado por Nietzsche.

No traçado da relação magistral que se estabelece entre essas duas produções, elas se encontram, por vezes, se tocam e, por fim, se completam como um verdadeiro par antípoda: o conceito de culpa que emerge com toda a sua força expressiva no cerce do cristianismo experienciado pela literatura de Saramago e o conceito de culpa que é diluído mediante a consolidação de um cristianismo que se pretendia autêntico, no qual 'pecado', 'culpa' e 'castigo' não possuíam mais lugar.

Nesse contexto, o pensador alemão desenvolve uma nova maneira de perceber 
o problema da representação estética do real que é, em certa medida, um problema ético, pontuando as inconsistências de certos modos de conceber o mundo, ao passo que faz emergir entendimentos diferentes sobre o universo judaico-cristão. Esse processo se dá a partir da delimitação de pensamentos desviantes que, nesse caso, tomam forma com base no discurso filosófico, então encarregado de esboçar a linha de fissura do saber culturalmente produzido.

Mais do que promover fissuras nas construções de mundo, neste caso, as premissas de Nietzsche operam diretamente no universo ficcional saramaguiano, desconstruindo seus valores estruturantes, processo que se dá à sombra de um pretenso modelo de "cristianismo autêntico". A suspensão dos juízos conceitualmente determinados se estabelece firmada na validade exemplar do discurso filosófico e não mais a partir da experiência do literário, essa última ainda cindida pela estreiteza das amarras ético-morais.

Inscritas nessa conjuntura, a Literatura e a Filosofia, tidas como formas de pensar envoltas em suas singularidades, ainda que não possam ser reduzidas uma a outra, ocupam uma mesma posição enquanto mediadoras entre culturas. A Literatura é então compreendida enquanto figuração estética e ética da sociedade, ao passo que a filosofia mantém uma relação estreita com a totalidade do real, o que se dá mesmo quando subversivamente e sem reservas promove fissuras na ordenação do mundo. Pensar a respeito da validade ou inconsistência desses valores nos permite significar e entender melhor a realidade que nos envolve, bem como, delimitar com novos contornos as tradições, ideologias e costumes convencionados ao longo dos séculos.

\section{REFERÊNCIAS BIBLIOGRÁFICAS:}

GIACÓIA, Oswaldo Jr. Nietzsche $e$ o Cristianismo. In: Revista Cult. N ${ }^{\circ} 88$ ano VII editora Daysi Bregantini: São Paulo, Janeiro de 2005.

HABERMAS, Jürgen. "Excurso sobre o Nivelamento da Diferença Genérica entre Filosofia e Literatura", in O Discurso Filosófico da Modernidade. Lisboa, Dom Quixote. 1990.

NIETZSCHE, Friedrich W. Genealogia da Moral. São Paulo: Companhia das Letras, 1998.

SARAMAGO, José. O evangelho segundo Jesus Cristo. São Paulo: Companhia das Letras, 2005. 